\title{
Do Princípio do Contorno Obrigatório e línguas faladas no Brasil
}

\author{
On the Obligatory Contour Principle and the languages \\ spoken in Brazil
}

\author{
Marília Facó Soares* \\ Universidade Federal do Rio de Janeiro \\ Gean Nunes Damulakis** \\ Universidade Federal do Rio de Janeiro
}

\begin{abstract}
Bringing into scene the theoretical route followed by The Obrigatory Contour Principle (OCP), Kaingáng; Parkatêjê; Je languages; Tonal languages, the present article has, among its aims: to contribute to the determination of the nature of such principle and to get evidence for a possible parameterization of it. In order to do so, we, based on specific phonological apects of some languages (genetically related or not) spoken in Brasil, will investigate them from the point of view of two interrelated theoretical questions which are still accepted, even in a representational model, and which refer to OCP evaluational contexts and its weakening from certain distances. The conclusions reached here allow us to sustain the hypothesis that the nature of OCP is linked to features involving articulation and perception. They also allow us to suggest that the OCP can be parameterized: its evaluation contexts can be minimally altered, according to the language, and its application is not affected by other restrictions with which it interacts.
\end{abstract}

\section{Keywords}

Phonology, OCP, Brazilian Portuguese, Indigenous languages, Tikuna 


\section{Resumo}

Trazendo à cena o percurso teórico do Princípio do Contorno Obrigatório (OCP), o presente artigo tem entre os seus objetivos o de contribuir para a determinação da natureza desse princípio e o de reunir evidências sobre sua parametrização ou não. Para tanto, toma por base determinados aspectos da fonologia de algumas línguas faladas no Brasil (genética e não geneticamente relacionadas) e as examina com base em duas questões teóricas inter-relacionadas que, ainda vigentes inclusive no contexto de um modelo representacional, referem-se aos contextos de avaliação de OCP e a seu enfraquecimento a partir de determinadas distâncias. As conclusões alcançadas permitem sustentar a natureza de OCP como estando ligada a uma propriedade de articulação e percepção. As conclusões incluem igualmente a afirmação de que OCP é parametrizado: seus contextos de avaliação podem se alterar minimamente conforme as línguas, não sendo, portanto, sua aplicação afetada apenas por outras restrições com as quais interage.

\section{Palavras-chave}

Fonologia, OCP, Português do Brasil, Línguas indígenas brasileiras, Tikuna, Kaingáng, Parkatêjê, Línguas Jê, Línguas tonais. 


\section{Introdução}

$\mathrm{O}$ conhecido Princípio do Contorno Obrigatório (doravante OCP) foi assim nomeado por Goldsmith (1976), com base em uma restrição discutida pela primeira vez por Leben (1973). Desde sua formulação original a partir de línguas tonais, OCP experimentou diferentes versões e levantou discussões no âmbito da fonologia auto-segmental. Concebido originalmente para impedir a existência de dois tons idênticos associados a vogais adjacentes, esse princípio - que já teve a sua força questionada com base em uma classe de contra-exemplos - foi mais de uma vez reformulado e chegou aos dias atuais sob concepções estendidas. Segundo uma dessas concepções, não estaria ele restrito às representações lexicais e atuaria no curso da derivação como uma força motriz que exerce pressão sobre regras fonológicas. Uma outra concepção também integrante da história de OCPé aquela em que, abandonando-se a referência à noção de camada auto-segmental como parte integrante da definição desse princípio, passa-se a lidar apenas com a noção de seqüência de elementos adjacentes. ${ }^{1}$

A parte da história de OCP que nos interessa é aquela em que esse princípio se enfraquece ou encontra limites para sua atuação. Isso porque estão entre nossos objetivos o de contribuir para a determinação de sua natureza e - ainda-o de reunir evidências que levem a uma resposta à questão de se OCP é parametrizado ou não. Se parametrizado, OCP deverá permitir diferentes contextos de avaliação. Em caso contrário, OCP terá sua aplicação afetada apenas por outras restrições com as quais interage. Para alcançar nossos objetivos, reunimos aqui evidências de línguas naturais que, faladas no Brasil, tiveram aspectos de sua fonologia diretamente (re)analisados pelos autores deste trabalho - as línguas Tikuna (isolada), Kaingáng e Parkatêjê (tronco Macro-Jê), além do português do Brasil.

\section{OCP: percursos teóricos e questões básicas}

Nas primeiras formulações de OCP (apresentadas em LEBEN, 1973; LEBEN, 1978), um elemento de uma melodia auto-segmental - um tom, um traço 
de harmonia vocálica, etc., - não podia ser adjacente a uma cópia de si próprio. Vem dessa época a mais conhecida configuração tornada impossível por OCP e vista em (1): em (1a), a adjacência tonal proibida está ligada à adjacência de unidades que portam o tom - no caso em (1a), um tom alto (A). Se a adjacência das unidades portadoras do tom não se faz presente, comoem (1b), OCP nãoé violadoe, conseqüentemente, a sequiência tonal idêntica é admitida. E, ainda, se a adjacência de unidades portadoras de tom não convive com dois tons idênticos adjacentes, mas apenas com um único tom associado a essas duas unidades - caso da configuração em (1c) -, OCP não é evidentemente violado e a seqüência em causa é permitida.

(1) OCP: configuração rejeitada e configurações admitidas.
a. $\quad * \ldots \times$ X
I I
b. XXX
c. XX
I 1
$1 /$
A A
A A
A

As configurações em (1) atravessaram o tempo e os modelos teóricos, ${ }^{2}$ cabendo notar que nelas o tom alto comparece apenas como exemplo, podendo estar em seu lugar um outro tom, um componente tonal ou, ainda, um traço não necessariamente ligado a tom. Essas configurações se encontram vinculadas a outras, representativas das estratégias existentes nas línguas para se alcançar conformidade a OCP. Vistas em (2), mediante exemplificações que oferecem determinadas línguas tonais, ${ }^{3}$ as estratégias mais comuns para se evitar violação $\mathrm{aOCP}^{4}$ sempre estiveram na dependência do tratamento que lhes deram diferentes modelos, em especial modelos derivacionais e modelos representacionais.

(2) Estratégias comuns para uma conformação a OCP

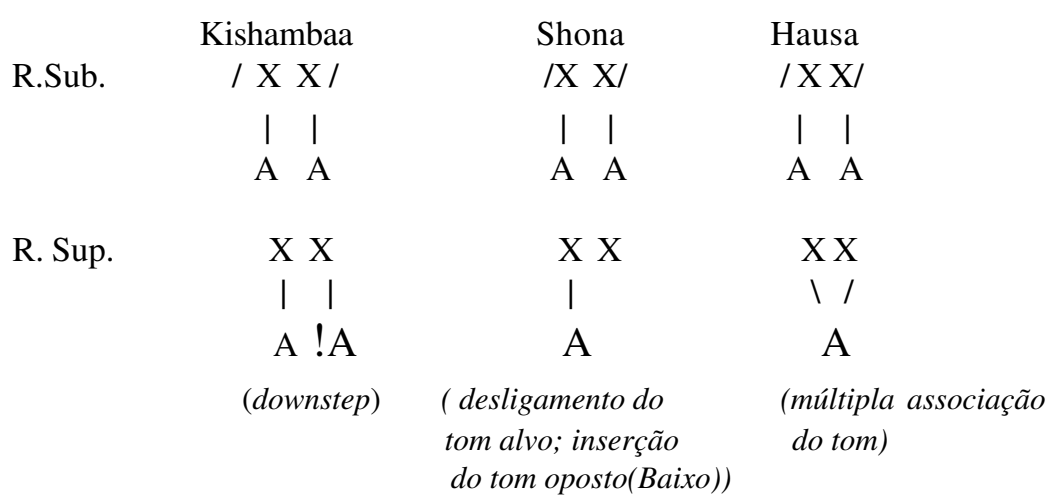


No que diz respeito à adjacência assinalada nas configurações em (1), já havíamos registrado em trabalho anterior ${ }^{5}$ que fatos específicos de determinadas línguas levaram alguns analistas a propor uma noção de adjacência estrutural com possível validade universal. Entre tais fatos estão, por exemplo, os vários casos dos efeitos da regra de Meeussen em línguas banto. Essa é uma regra que envolve o apagamento de tom alto associado à próxima sílaba, e nunca o apagamento do próximo tom alto na camada tonal. A formulação da regra de Meeussen pode ser vista em (3), estando em (4) e (5), respectivamente, uma exemplificação de sua aplicação e não-aplicação.

(3) Regra de Meeussen

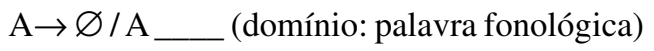

(4) língua Shona, dialeto Zezuru: aplicação da regra de Meeussen

$$
\text { v-á- teng-es-a }
$$

(3p.pl.- passado) - (comprar-caus-vogal final)

'eles venderam (hoje)'

Palavra fonológica: input

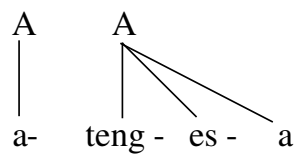

Palavra fonológica: aplicação da regra de Meeussen

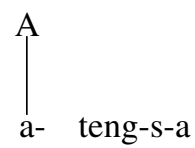

(5) língua Shona,dialeto Zezuru: não-aplicação da regra de Meeussen<smiles>[Te][Te][Te][Tl]</smiles>

(cf. MEYERS, 1987)

(('com'- (3) - (' medicina')) 'com medicina'

(némutí, cf. *némuti) 
É a uma concepção estrita de adjacência que se deve a não-aplicação da regra de Meeussen em (5): aí os tons altos em jogo não são adjacentes, porque: (i) não se encontram associados a sílabas adjacentes, isto é, a unidades portadoras de tom adjacentes; (ii) não participam de uma configuração em que pelo menos um dos dois tons não está associado - situação em que a adjacência entre um e outro seria definida na camada a que ambos pertencem (no caso, a camada tonal).

A concepção estrita de adjacência garantiu, para as línguas banto, a permanência teórica de OCP, uma vez que casos semelhantes a (5) foram retirados da condição de violadores desse princípio, na medida em que tons idênticos em sequiência na sua camada não seriam, na realidade, adjacentes. $\mathrm{Na}$ prática, isso conduziria a um enfraquecimento de OCP. Esse enfraquecimento foi defendido por Odden (1986), que advogou a adjacência estrita e o rebaixamento de OCP de princípio a regra. ${ }^{6}$ Já Yip (1988) sustentou OCP como restrição universal sobre regras fonológicas, restrição que tanto bloqueia quanto desencadeia regras e que, ainda, poderia condicionar a aplicação de uma regra que, de outra forma, seria ambígua. ${ }^{7}$ Vale ressaltar que a discussão sobre a necessidade ou não de enfraquecer OCP se deu no contexto de uma fonologia auto-segmental marcadamente derivacional e que essa questão muda de ângulo, quando o contexto teórico é o de um modelo representacional, como no caso da Teoria da Otimalidade. Aqui os limites para a atuação de OCP nascem da interação entre restrições, OCP sendo ele próprio uma restrição violável cuja força de atuação depende, em princípio, de seu lugar em hierarquias de restrições vigentes em línguas particulares.

Embora a questão do enfraquecimento ou não de OCP tenha sido reposicionada, em termos teóricos duas questões inter-relacionadas ainda permanecem, mesmo no contexto de um modelo representacional, quais sejam: 1) Quais os contextos de avaliação de OCP? 2) Há enfraquecimento de OCP a partir de determinadas distâncias? Essas são questões abertas que, encontradas em trabalhos sobre aquisição fonológica, ${ }^{8}$ conjugam-se à natureza de $\mathrm{OCP} \mathrm{e}$ revelam-se importantes para a teoria fonológica. São elas que nos guiam no exame das línguas a seguir. 


\section{Línguas faladas no Brasil}

\subsection{Tikuna}

O Tikuna é falado na Amazônia ocidental, estando a maior parte de sua população no Brasil. ${ }^{9}$ Considerada como geneticamente isolada, é uma língua tonal em que Soares (1996) identificou uma restrição capaz de ser associada a bloqueio de processos. Essa restrição foi identificada como OCP (Princípio do Contorno Obrigatório), cuja formulação em (6) proíbe uma sequiência de especificações tonais idênticas, conforme Soares (2003), que aqui retomamos:

(6) Tikuna (língua tonal, isolada - Amazônia ocidental/Brasil, Peru e Colômbia)

OCP: é proibido haver uma seqüência de especificações tonais idênticas

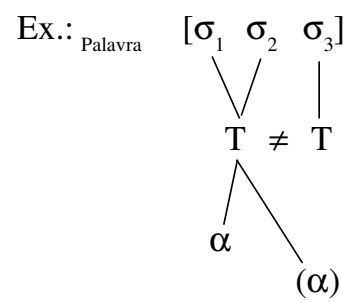

De acordo com (6), a terceira sílaba de uma palavra não pode ser associada ao mesmo componente tonal da segunda sílaba, sempre que esse componente estiver associado à primeira sílaba através do nódulo tonal. Para que os efeitos bloqueadores do OCP tenham lugar, OCP deve estar acima da restrição INTERPRETABILIDADE (ver 7) - que requer a presença de tom em todas as vogais:

(7) INTERPRETABILIDADE (TOM): todas as vogais devem portar um tom.

Arestrição de INTERPRETABILIDADEdesencadeia não somente processos de propagação tonal, mas também a especificação default. No final da hierarquia está uma restrição relacionada à fidelidade entre representação subjacente (input) e representação superficial (output) - MAX-IO (T), ${ }^{10}$ vista em (8):

(8) MAX-IO (T): um tom no input deve possuir um correspondente no output.

Facilmente violável em Tikuna, essa última restrição exige que cada traço/ componente tonal no input possua um correlato no output. A escala hierárquica envolvendo essas três restrições está em (9): 
(9) OCP $>$ INTERPRETABILIDADE $>$ MAX-IO.

E a ilustração de seus efeitos encontra-se em (10) e (11): ${ }^{11}$

(10) Input: /i/ / tit/ /ma/ / / / aspecto - 3p.íntima - matar - nominalizador 'ele [a] surrou",

\begin{tabular}{|c|c|c|c|}
\hline $\begin{array}{cccc}/ \mathrm{i} & - & \mathrm{ti}- & \mathrm{ma}-\tilde{\mathrm{f}} / \\
\mid & \mid & \mid & \mid \\
\mathrm{A} & \mathrm{A} & \mathrm{B} & \mathrm{A}\end{array}$ & OCP & INTERPRETABILIDADE & MAX -IO (T) \\
\hline a) $\begin{array}{l}\mathrm{i} \\
\mid \mathrm{t}\end{array}$ & $* !$ & & \\
\hline 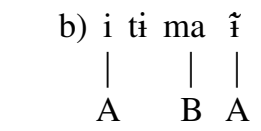 & & $* !$ & $*$ \\
\hline c) i ti ma $\tilde{\mathrm{f}}$ & $* !$ & & $*$ \\
\hline 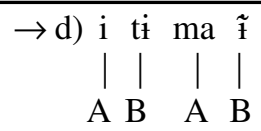 & & & $* * *$ \\
\hline $\begin{array}{l}\text { e) } \mathrm{i} \text { ti } \mathrm{ma} \tilde{\mathrm{t}} \\
||_{\mathrm{B}}\end{array}$ & $* !$ & & $* *$ \\
\hline
\end{tabular}

(11) Input: /i tsa na pa/ aspecto-1p.s.objeto interno- secar 'eu o seco'

\begin{tabular}{|c|c|c|c|}
\hline $\begin{array}{cccc}\text { i } & \text { tsa } & \text { na } & \text { pa / } \\
\mid & & & \mid \\
\mathrm{A} & & & \mathrm{A}\end{array}$ & $\mathrm{OCP}$ & INTERPRETABILIDADE & $\operatorname{MAX}-\mathrm{IO}(\mathrm{T})$ \\
\hline a) ${ }_{\text {i }}$ tsa na pa & *! & $* *$ & \\
\hline b) i tsa na pa & & $* ! *$ & * \\
\hline$\rightarrow \mathrm{c})$ i tsa na pa & & & $*$ \\
\hline
\end{tabular}


As formas ótimas em (10)e (11) são outputs que exibem alternâncias tonais. Vale ressaltar que, em (11), verifica-se que a língua Tikuna exibe um comportamento diferente das línguas banto no que diz respeito a OCP. Diferentemente dessas últimas, em Tikuna violações a OCP são identificadas diretamente na camada tonal, não havendo dependência de adjacência silábica estrita. ${ }^{12}$ Quanto à colaboração entre altura e acento (manifestado em Tikuna pela duração longa, conforme Soares $(1992,1999,2001))$, vejamos o quadro em (12):

$$
\begin{aligned}
& \text { Input: [[[nuki] its i] ma] tempo-intensificador }{ }_{1} \text { - } \text { intensificador }_{2} \\
& \text { l I l l । } \\
& \text { B A A B A 'muito, muito tempo' }
\end{aligned}
$$

\begin{tabular}{|c|c|c|}
\hline $\begin{array}{l}\text { / nuki }-\mathbf{- i} \text { tsi }-\mathrm{ma} / \\
\begin{array}{ccccc}\mid & \text { | } & \text { I } & \text { | } & \text { | } \\
\text { B } & \text { A A } & \text { B } & \text { A }\end{array}\end{array}$ & $\begin{array}{l}\text { ALINHAR } \\
\text { RAIZ-PÉ }\end{array}$ & *SEM PÉ \\
\hline 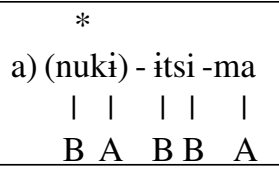 & & $* * *$ \\
\hline 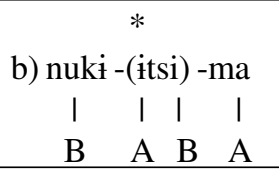 & $* !$ & $* * *$ \\
\hline $\begin{array}{ccccc}* & * & & \\
\text { c) }(\text { nuk } & \text { i) } & -(\text { itsi)-ma } \\
\text { I } & \text { | } & \text { I } & \text { I } & \text { | } \\
\text { B } & \text { A } & \text { A } & \text { B } & \text { A }\end{array}$ & & $*$ \\
\hline $\begin{array}{cccc} & * & * \\
\text { d) }(\text { nuk }) & -(\text { its } & \text { i) } & \text { ma } \\
\text { I } & \text { | } & \text { | } & \text { | } \\
\text { B } & \text { A } & \text { B } & \text { A }\end{array}$ & & $*$ \\
\hline $\begin{array}{llll} & * & & \\
\text { e) } & (\text { nuk }) & \text {-its } & \text { i }-m a \\
\text { । } & \text { । } & \text { I } & \text { | } \\
\text { B } & \text { A } & \text { B } & \text { A }\end{array}$ & & $* * *$ \\
\hline
\end{tabular}

(Obs.: colchetes indicam a constituição interna das palavras; parênteses indicam pé métrico; * sobreposto $=$ acento lingüístico abstrato; * sobreposto $=$ acento rítmico)

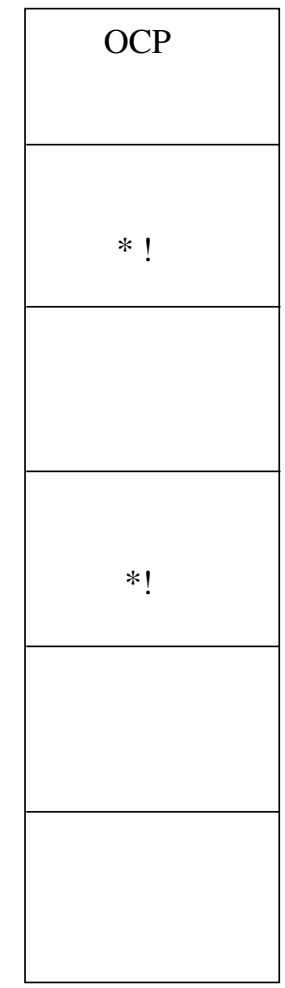

ALINHAR RAIZ -PÉ :alinhar sílaba mais à esquerda da raiz com acento *SEM PÉ - proíbe sílabas não-analisadas em pé 
Em (12), há uma restrição de alinhamento responsável pelo aparecimento de acento na sílaba mais à esquerda da raiz. Essa restrição supera uma outra SEM PÉ - que proíbe sílabas não-analisadas em pé. É importante dizer que essa última restrição é afetada por OCP - uma restrição independente que é responsável pela criação, em Tikuna, de outputs com alternâncias tonais. Por exemplo, em (12), de um lado se tem a eliminação dos candidatos a) e c) por OCP, enquanto o candidato $b$ ) - que respeita $\mathrm{OCP}$ - é descartado pela restrição que alinha raiz e pé: o acento em (12 b) não está alinhado com a raiz. Por outro lado, os candidatos $d$ ) e $e$ ) podem ser considerados como ótimos, embora $e$ ) viole SEM PÉ muito mais do que o candidato $d$ ). Esse fato pode ser explicado pela interferência de OCP: restrição independente em relação àquela responsável pela existência de um acento na sílaba mais à esquerda da raiz, OCP somente poderia interferir no resultado da avaliação feita por SEM PÉ se a qualidade de sua interferência tivesse efeitos que contrabalançassem possíveis violações de SEM PÉ. Do nosso ponto de vista, se um output como e) em (12) - que apresenta múltiplas violações de SEM PÉ - ainda pode ser considerado como candidato ótimo (juntamente com um outro candidato $-d$ ) - que viola em menor extensão a mesma restrição), é devido à existência dos efeitos de OCP. Esses efeitos, que contrabalançam violações de outra restrição, teriam origem na natureza perceptual de uma restrição ou família de restrições chamadas OCP. Devido às evidências empíricas, temos uma boa razão para dizer que, em Tikuna, as fronteiras entre tom e acento estão sujeitas a uma interferência perceptual. Em Tikuna, o tom não é capaz de criar estrutura métrica, mas é capaz, em circunstâncias bastante específicas, de suprir uma necessidade acentual. ${ }^{13}$ Uma representação formal dessa conclusão pode ser vista em (13):

(13) Tikuna: hierarquia entre restrições prosódicas e tonais

$$
\begin{aligned}
O C P> & >\text { INTERPRETABILIDADE }>>\text { MAX-IO(T) }>>\text { ALINHAR RAIZ - PÉ }>>\text { SEM PÉ } \\
\text { (Restrições tonais) } & \text { (Acento }- \text { Restrições prosódicas) }
\end{aligned}
$$

Na realidade, em (12), como os candidatos $a$ ) e $c$ ) são eliminados por OCP independentemente de SEM PÉ e como OCP não é dominada por ALINHAR RAIZ-PÉ, parece bastante razoável propor a hierarquia em (13) . Em termos das questões que nos guiam, resta dizer que, em Tikuna, OCPé uma restrição não-dominada de caráter perceptual, que tem, como seu contexto de avaliação, a palavra fonológica. É importante ressaltar que a distância a ser 
observada por OCP não impõe a observação da adjacência silábica estrita, mas não ultrapassa o limite de duas sílabas - conforme revelam os dados.

\subsection{Kaingáng}

No Kaingáng, língua do tronco Macro-Jê, integrante da família Jê e falada no sul do país, detectamos a inexistência de seqüências de segmentos consonantais coronais ou contínuos na mesma sílaba. Conforme se vê em (14), no Kaingáng, há os seguintes segmentos consonantais: ${ }^{14}$

(14) Segmentos consonantais do Kaingáng

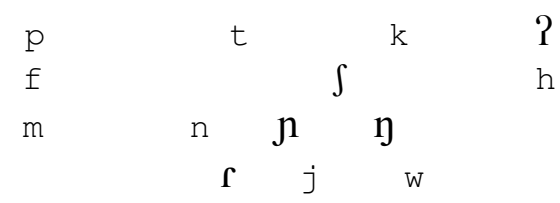

Dos segmentos acima, apenas / $/$, que é [coronal $]^{15}$ e [+contínuo], pode ser o segundo elemento de um onset complexo. Nesse caso, nenhuma outra consoante [coronal] poderá ocupar a primeira posição, o que barra seqüências tais como */tr/, */nr/ ou */nr/, por exemplo. Também não ocorre como primeira posição uma outra consoante [+ contínua]. Isso quer dizer que seqüências como /fr/, / $\mathrm{f} /$ não ocorrem na língua (sendo / $\mathrm{s} /$ também proibida por constituir uma seqüência de segmentos [coronais] adjacentes). Ainda pensando em seqüências de elementos [+ contínuos], pode-se constatar que inexistem sequiências como $* / \mathrm{rj} /$, */rw/ ou $* / \mathrm{jj} /$ ou $* / \int \mathrm{w} /$.

É possível alargar essa proibição, sustentando que é ela que impede sequiência de segmentos consonantais igualmente [-contínuos], o que é comprovado pela inexistência da contigüidade de segmentos tais como/p/,/t/, $/ \mathrm{k} /, / \mathrm{m} / \mathrm{e} / \mathrm{n}$, por exemplo. Em outras palavras, inexistem na língua sequiências como $* / \mathrm{pt} /, * / \mathrm{kp} /, * / \mathrm{kt} /, * / \mathrm{nt} / \mathrm{ou} * / \mathrm{mp} /$. Nesse caso, deve-se propor que a proibição é válida para segmentos igualmente valorados para o traço [contínuo]. Sendo assim, pode-se dizer que o OCP impede, no Kaingáng, seqüências de segmentos consonantais entre si, igualmente coronais e igualmente [ $\alpha$ contínuos]. Vê-se, em (15a), a escala hierárquica proposta para o Kaingáng e da qual constam as seguintes restrições: MAX-IO, que avalia a relação entre input e output, proibindo apagamentos; ONSET, proibidora de sílabas sem onset, ou seja, sem ataque; COMPLEX ${ }^{\mathrm{CODA}}$, que milita contra a complexidade em codas (ou 
declives); *CODA[-nasal], que interdita codas não nasais; OCP [a contínuo], inibidora da contigüidade de elementos com o mesmo valor para o traço [contínuo]; OCP [coronal], que milita contra elementos contíguos coronais; *COMPLEX ${ }^{\mathrm{ONSET}}$, que proíbe onsets, ou ataques, complexos; DEP-IO, que, ao verificar a relação entre input e output, proíbe inserções. Em (15b), exemplificase a seleção de um item lexical como [krîn] 'estrela' ${ }^{16}$

(15) Escala hierárquica e restrições atuantes no Kaingáng

a) MAX-IO $>>$ ONSET, $*$ COMPLEX ${ }^{\mathrm{CODA}} \gg>$ CODA[-nasal $] \gg>$ OCP $[\alpha$ contínuo], OCP [coronal] $>>*$ COMPLEX $^{\mathrm{ONSET}}>>$ DEP-IO.

b) Seleção do item [krĩn] 'estrela'

\begin{tabular}{|c|c|c|c|c|c|}
\hline Input: krĩn & ONS $*{ }^{*}$ COMP & ${ }^{*}$ CODA[-nas] & OCP $[\alpha$ cont $]$ & OCP[cor] & *COMP ${ }^{\text {ONS }}$ \\
\hline a. krĩg & & $* !$ & & & \\
\hline b. trĩn & & & & $* !$ & \\
\hline c. krĩn & & & & & * \\
\hline 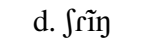 & & & $* !$ & & \\
\hline
\end{tabular}

Em Kaingáng, OCP atua como uma família de restrições, e sua atuação está diretamente ligada à proibição da adjacência (estrita) de segmentos consonantais, no domínio da sílaba. Em realidade, podemos afirmar que OCP atua no nível subsegmental, proibindo a contigüidade de segmentos especificados e/ ou igualmente valorados para os traços [coronal] e [contínuo]. Em outros termos, atua no âmbito do ponto de articulação consonantal (através do traço [coronal]) e no da cavidade oral (por meio do traço [contínuo]).

\subsection{Parkatêjê}

No caso do Parkatêjê - língua do tronco Macro-Jê, pertencente à família Jê e falada no sudeste do Pará -, pode-se dizer que OCP atua de forma bastante similar no que se refere à constituição silábica. Confira-se, em (16), o inventário fonológico do Parkatêjê, conforme se pode ver em Araújo (1989): 
(16) Segmentos consonantais do Parkatêjê

$\begin{array}{cccccc}\mathrm{p} & \mathrm{t} & & \mathrm{k} & & \text { ? } \\ \mathrm{m} & \mathrm{n} & & & & \\ & & & & & \\ & & \mathrm{t} j & & & \mathrm{~h} \\ & \mathrm{r} & \mathrm{j} & \mathrm{w} & \end{array}$

Uma vez que não há na língua em causa onset complexo do tipo */tr/ ou */ns/, pode-se postular que haja uma restrição fonotática proibindo essa seqüência, ou seja, uma seqüência de dois segmentos [coronais] adjacentes. Note-se que: (a) essa sequiência não seria proibida pela escala de sonoridade, já que $/ \mathrm{n} /$ é menos sonoro que $/ \mathrm{r} /$; e (b) a proibição não é para a existência de consoante nasal como primeiro elemento de um grupo consonantal, uma vez que há itens na língua como mra 'chorar'. Vale ressaltar também que a proibição não afeta a ocorrência de itens nos quais o segmento $/ \mathrm{n} / \mathrm{seja}$ o primeiro elemento de um suposto onset complexo, como nos mostrariam palavras como "nkôti"/nkoti/ 'gongo' (ARAÚJO, 1989), pois o segmento/k/ nãoé [coronal], e sim [dorsal]. Além disso, essa nasal não faz parte da mesma sílaba em que a dorsal se encontra, sendo, segundo interpretamos em Damulakis (2006), uma nasal silábica, núcleo, portanto, de sílaba (ou seja,/nn.ko.ti/). Ressalte-se que OCP atua impedindo apenas sequiência de coronais tautossilábicas, o que é comprovado pela existência de itens como “inxum" /in.tfum/ 'meu pai', conforme comunicação pessoal de Araújo.

Também em comunicação pessoal, Araújo nos forneceu ainda o item "ntia" 'mulher', e há, em Araújo (1989), o item “ntoj” 'correr'. Esses últimos itens devem ser interpretados como contendo uma seqüência com nasal silábica, ou seja, nasal núcleo de sua própria sílaba. Interpretar essa sequiência como um onset complexo contrariaria a escala de sonoridade, escala bastante respeitada na língua, além de supostamente levar à admissão da contigüidade de elementos tautossilábicos coronais - algo que a língua rejeita, como exposto anteriormente. Assim sendo, os itens em causa acima devem ser interpretados como /n.tia/ e /n.toj/, o que importa em respeito à escala de sonoridade e valida OCP para o traço [coronal].

Com relação ao onset complexo, é possível dizer que, no Parkatêjê, podem figurar como segundo elemento de um onset complexo apenas os glides e a vibrante. Logo, os outros segmentos consonantais só podem ocupar a primeira posição. Segundo a análise de Araújo, as nasais podem ocupar uma posição de 
primeira consoante de um grupo tautossilábico consonantal. Essa análise contrasta com aquela que defendemos anteriormente, a de que a nasal nesse contexto é silábica. Ao defender a silabicidade da nasal nesse contexto, evita-se, por um lado, desrespeitar a escala de sonoridade, já que depois dessa nasal viria uma consoante oclusiva, menos sonora, portanto; e, por outro lado, evita-se o desrespeito a OCP para traço [coronal], para um contexto em que a consoante seguinte seja /t/, por exemplo.

As sequiências */tr/, */t $\int \mathrm{r} / \mathrm{e} * / \mathrm{n} r /$ são vetadas por OCP para o traço [coronal]. O mesmo seria válido para as sequiências $* / \mathrm{tj} /$, * $/ \mathrm{t} \mathrm{j} / \mathrm{e} * / \mathrm{nj} /$. Os efeitos dissimilatórios de OCP para ponto parecem ser bastante fortes no Parkatêjê, uma vez que também está proibida a sequiência de segmentos adjacentes que tenham em comum o traço [labial], como nos mostra a inexistência de */pw/ e */mw/. Assim sendo, faz-se necessário considerar que OCP atua também proibindo a contiguiidade de segmentos tautossilábicos [labiais]. Ressalte-se, mais uma vez, que a atuação de OCP é mais forte no interior de um mesmo domínio. Observese, em (17a), as restrições que operam no Parkatêjê, entre as quais se encontram SON, que obriga que a configuração da sílaba respeite a escala de sonoridade; e *CODA, que proíbe a existência de coda. Em (17b), ${ }^{17}$ temos a seleção de um item lexical como [krejre] 'espécie de tatu'.

(17) Escala hierárquica e restrições atuantes no Parkatêjê

a) SON $>>$ MAX-IO $>$ ONSET $>>$ OCP [coronal], OCP [labial] >> *COMPLEX ${ }^{\mathrm{CODA}}>>*$ COMPLEX $^{\mathrm{ONSET}}>>$ DEP-IO, ${ }^{*}$ CODA

b) Seleção do item [krejre] 'espécie de tatu'

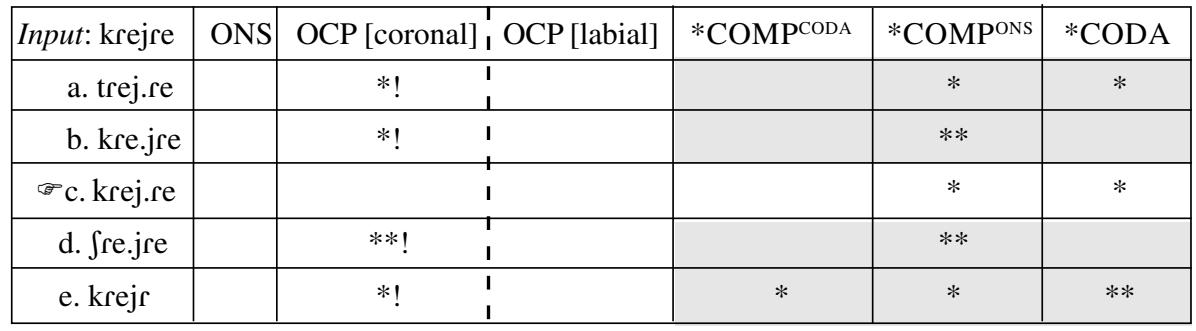

Tal como no Kaingáng, o domínio de atuação de OCPé a sílaba, havendo igualmente exigência de adjacência estrita. Entretanto, comparado ao Kaingáng, o Parkatêjê apresenta o fortalecimento de OCP, não apenas no que tange à sua posição na escala hierárquica, como também em seu desdobramento no que diz 
respeito a ponto de articulação - o que continua a apoiar a idéia de OCP como uma família de restrições. Note-se que há proibição também para a contigüidade de segmentos labiais tautossilábicos em Parkatêjê.

\subsection{Português do Brasil}

Conforme Damulakis (2005), há dois tipos de monotongação bastante recorrentes e abrangentes no português do Brasil, resultantes da não-realização/ apagamento dos glides anterior e recuado: $[\mathrm{ej}]>[\mathrm{e}] \mathrm{e}[\mathrm{ow}]>[\mathrm{o}]$. Até certo ponto, é possível fazer uma analogia estrutural entre esses dois tipos, sobretudo concernentemente ao fato de que o glide apagado é homorgânico à vogal-base do ditongo. Entretanto, há uma assimetria entre esses dois fenômenos, pois é possível atestar que a monotongação decorrente do apagamento do glide posterior é mais abrangente que aquela decorrente da supressão do glide [j].

Essa assimetria está intimamente relacionada à atuação de OCP, uma vez que a monotongação é um efeito dissimilatório derivado desse princípio. OCP atua, porém, de forma assimétrica e não-análoga: no caso da monotongação [ej] > [e], a supressão ocorre entre sílabas, sendo o glide suprimido diante de alguns fonemas que o seguem e com os quais tem alguns traços em comum. Já para a monotongação [ow] $>[\mathrm{o}]$, a redução ocorre devido à contigüidade de elementos tautossilábicos com traços em comum.

A inexistência de supressão do glide diante de pausa, como nos itens 'rei', 'lei', mostra que a monotongação [ej] > [e] é determinada pela presença de segmentos adjacentes à direita. Os segmentos que mais favorecem esse tipo de

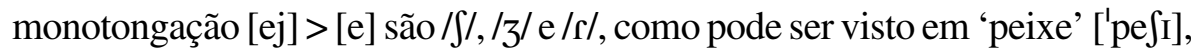
'beijo' ['bezu] e 'beira' ['berc]. Uma das características que esses segmentos têm em comum com o glide anterior é a coronalidade, além de valor negativo para o traço subarticulatório [anterior] e valor positivo para o traço [contínuo], pelo menos para os dois primeiros segmentos acima $(/ \mathrm{J} /, / 3 /) .{ }^{18}$ Diante de outros segmentos, não ocorre sistematicamente a redução desse ditongo, como mostram itens como 'beiço' ['bejzu], 'peito' ['pejtu], 'leigo' ['lejgu], nos quais a redução não se dá. Os segmentos $/ \delta /, / 3 /, / \mathrm{r} / \mathrm{e} / \mathrm{j} /$ têm em comum, além do traço [coronal], os traços [-aberto1] e [-aberto2]. Podemos ver em (18) o contexto em que OCP atua. 
(18) Contexto para atuação de OCP na redução [ej] > [e]

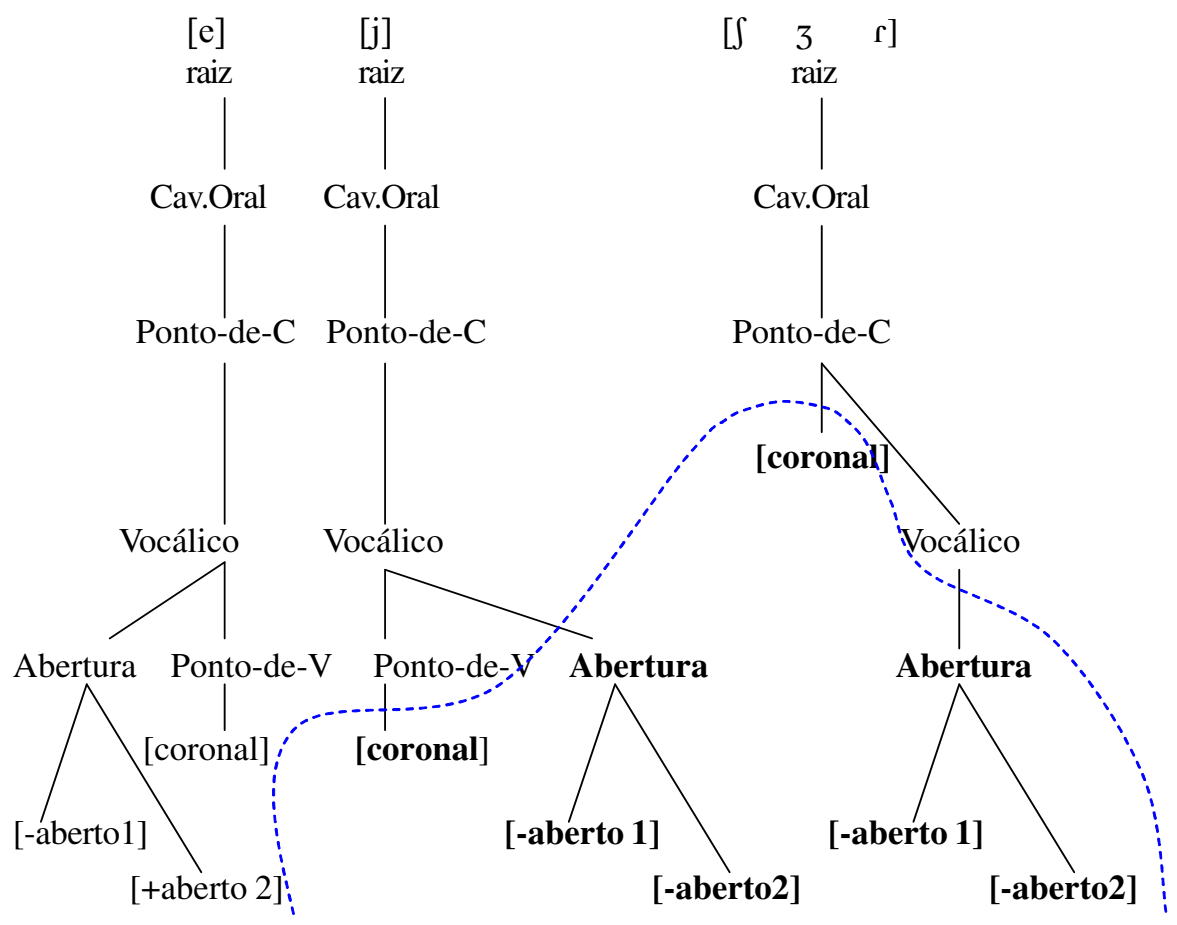

A redução [ow] > [o] é categórica, não importando o contexto seguinte: 'touca' ['toke], 'poupa' ['pope], 'louça' ['lose], por exemplo. A redução ocorre mesmo em final de palavra, como em 'catou' [ka'to], 'vou' ['vo], 'sou' ['so], o que significa que a supressão do glide não leva em consideração o contexto seguinte, mas o contexto tautossilábico. Possivelmente a labialidade e talvez mesmo a dorsalidade ${ }^{19}$ dos segmentos $/ \mathrm{o} / \mathrm{e} / \mathrm{w} /{ }^{20}$ é o que determina a supressão do glide recuado. Pode-se ver em (19) o contexto de atuação para essa supressão: 
(19) Contexto para atuação de OCP na redução [ow $]>[0]$

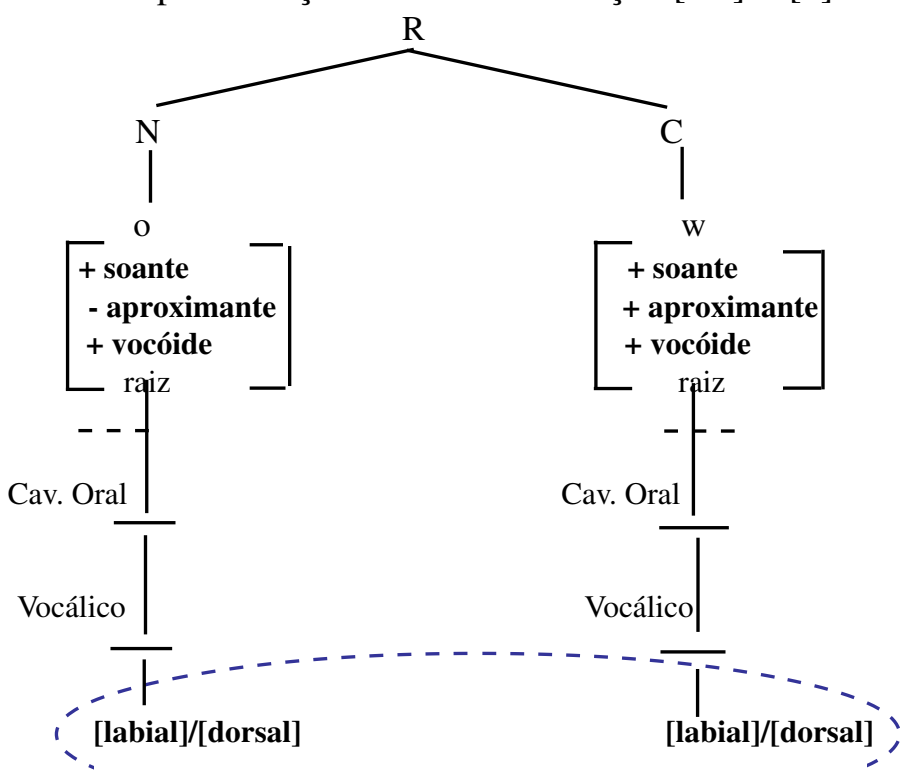

A confrontação em final absoluto de palavra fornece dados capazes de sustentar a diferença do tratamento da atuação de OCP em [ej] e [ow]. Itens como 'catou' [ka'to] e 'vou' ['vo], por um lado, e 'lei'[lej] e 'paguei' [pagej], por outro, sugerem que OCP é atuante no português e atinge contextos distintos na língua. No primeiro contexto, atua proibindo a adjacência de elementos tautossilábicos labiais; no último, OCP proíbe elementos heterossilábicos adjacentes que sejam igualmente [coronais], [-abertos 1] e [-abertos 2].

Com base na da assimetria da atuação de OCP nas reduções de/ej/e /ow/ , pode-se dizer que tal princípio atua de forma mais abrangente no interior de um mesmo domínio, ao passo que tem sua atuação enfraquecida entre domínios. Notese que a monotongação [ow] > [o] é mais abrangente, pois está condicionada à proibição da contigüidade de elementos na mesma sílaba. Já a redução [ej] > [e] é mais restrita, pois está condicionada à adjacência de elementos heterossilábicos.

O mesmo princípio também está por trás de um fenômeno recorrente em algumas variedades do português de Brasil, a saber: a determinação do ponto de articulação da sibilante pós-vocálica. Nas referidas variedades, a sibilante [s] sobrevive sempre que não haja adjacentemente uma outra consoante especificada com os mesmos traços [coronal] e [+anterior]; caso contrário, a sibilante [S] terá lugar. Esse seria o caso de realizações [s] (ou [z]) para a sibilante diante de 
consoantes que não sejam coronais, tais como [k], [g], [p], [b], [m], conforme se pode ver em ['kaske], ['hazge], ['aspes], [ezbura'kadu], ['mezmu], para 'casca', 'rasga', 'aspas', 'esburacado' e 'mesmo', por um lado; entretanto, diante de consoantes coronais e [+anteriores], tais como [t], [d], [n] e [1], são realizadas as sibilantes coronais [-anteriores] [S] ou [3], conforme se pode ver em ['aftru], [dez'dite], ['aznu], [traz'ladu], para 'astro', 'desdita', 'asno', 'traslado'. Nesse caso, a dissimilação se dá pelo ponto de articulação e, ainda, por uma subarticulação ligada ao traço [coronal], a saber: [+/- anterior].

Uma das vantagens de OCP é a possibilidade de interpretar seus efeitos tanto dentro de uma análise derivacional quanto em uma não-derivacional. No primeiro caso, pode-se postular uma regra que expresse o processo fonológico em que OCP atua; no segundo, como seria o caso de uma análise pela teoria da otimalidade, pode-se postular uma restrição, que, a depender de sua posição na escala hierárquica, poderá restringir realizações que violem o princípio.

Na teoria da otimalidade, OCP poderia ser interpretado como uma família de restrições, que poderiam atuar de forma específica em cada língua natural. No caso das monotongações do português aqui mostradas, estariam atuando duas restrições dessa família: OCP [coronal] e OCP [dorsal]/[labial].${ }^{21}$ Abaixo vemos exemplos retirados de Damulakis (2005):

(20) Variante monotongada [e]

\begin{tabular}{|c|c|c|c|}
\hline Input: /bej3v/ & $\begin{array}{c}\text { IDENT-IO } \\
\text { [+aberto 2] }\end{array}$ & $\begin{array}{c}\text { OCP[coronal] } \\
\text { e [aberto] }\end{array}$ & MAX-IO \\
\hline (a) b[e].jo & & $* !$ & $*$ \\
\hline (b) b[ej].jo & & & $*$ \\
\hline (c) b[i].jo & $* !$ & $*$ & \\
\hline (d) b[ij].jo & $* !$ & & \\
\hline
\end{tabular}

(21) Variante monotongada [o]

\begin{tabular}{|c|c|c|c|}
\hline Input:/powku/ & $\begin{array}{c}\text { IDENT-IO } \\
\text { [+aberto 2] }\end{array}$ & $\begin{array}{c}\text { OCP[labial] } \\
\text { e [aberto] }\end{array}$ & MAX-IO \\
\hline (a) ' $\mathrm{p}[\mathrm{o}] . c o$ & & & $*$ \\
\hline (b) ' $\mathrm{p}[\mathrm{ow}] . c o$ & & $* !$ & \\
\hline (c) ' $\mathrm{p}[\mathrm{u}] . c o$ & $* !$ & & $*$ \\
\hline (d) $\mathrm{p}[\mathrm{uw}] . c o$ & $* !$ & & $*$ \\
\hline
\end{tabular}


Nos quadros apresentados, os candidatos que contenham os glides $/ \mathrm{j} / \mathrm{e}$ /w/ são eliminados por violarem as restrições OCP [coronal] e OCP [dorsal]/ [labial], respectivamente.

\section{Conclusão}

Em Tikuna, OCP possui atuação no plano tonal, onde impede seqüência de especificações tonais idênticas e compensa indiretamente uma necessidade acentual. OCP é aí uma restrição não-dominada de caráter perceptual, que tem, como seu contexto de avaliação, a palavra fonológica. Não impõe a observação da adjacência silábica estrita, mas não ultrapassa o limite de duas sílabas - o que significa que, de alguma forma, há uma distância perceptual mínima para a sua atuação.

Em Kaingáng, OCP impede uma seqüência de dois segmentos [coronais] e, ainda, de elementos com valor idêntico para o traço [contínuo], havendo consequiência direta sobre o onset (ataque) silábico complexo. Algo semelhante ocorre no Parkatêjê, sendo que aí OCP também alcança o traço [dorsal]. Em ambas as línguas, OCP atua como uma família de restrições; sua atuação está diretamente ligada à proibição da adjacência (estrita) de segmentos consonantais, no domínio da sílaba.

Com relação ao português do Brasil, é devido a um fenômeno dissimilatório derivado de OCP que ocorrem as monotongações [ej] $>[\mathrm{e}]$ (atuação intersilábica) e [ow] $>[o]$ (atuação tautossilábica). Também se vincula a OCP a realização da sibilante pós-vocálica - fenômeno recorrente em variedades do português do Brasil. Podemos dizer que OCPé categórico quando seu domínio é a sílaba, como no caso da redução [ow] $>$ [o], ao passo que se torna enfraquecido quando envolve elementos entre sílabas, o que ocorre com a monotongação [ej] > [e].

O elemento comum entre as línguas analisadas é que OCP necessita, para a sua atuação, de uma distância mínima: em Tikuna, a distância entre tons idênticos não deve ser maior do que duas sílabas, para que uma forma lingüística possa passar pelo crivo de OCP. Em Kaingáng e Parkatêjê, o nível de inspeção de OCP é tautossilábico. Em português, uma atuação intersilábica é menos abrangente do que uma tautossilábica. Entendemos que isso se deva à natureza de OCP, ligada a uma propriedade - pelo que indicam as línguas aqui apresentadas - de articulação e percepção. Os contextos de avaliação de OCP, ao que tudo indica, podem se alterar minimamente conforme as línguas - o que mostra ser 
OCP parametrizado. Com isso, a sua aplicação não é afetada apenas por outras restrições com as quais interage.

\section{Notas}

* Professora do Museu Nacional/UFRJ, com atuação nos Programas de Pós-Graduação em Lingüística e Antropologia Social, ambos da UFRJ. Pesquisadora do CNPq.

** Doutorando em Lingüística (UFRJ) e estagiário do Museu Nacional/UFRJ (Departamento de Antropologia, Setor de Lingüística), com atividades docentes desenvolvidas na Faculdade de Letras/UFRJ (Graduação). Bolsista do CNPq (Doutorado).

${ }^{1}$ Pela definição já tradicional de OCP, elementos idênticos adjacentes em uma mesma camada estão proibidos. Ao ser abandonada a noção de camada auto-segmental como parte da definição de OCP, são elementos idênticos em seqüência (como sílaba, raiz, traços) que se tornam não permitidos (como na proposta de Suzuki (1998)).

${ }^{2}$ Confira-se a permanência dessas configurações em autores como Goldsmith (1976), Odden (1986), Yip (1988), Myers ( 2004 [1995]).

${ }^{3}$ As línguas em questão são: o Kishambaa, língua banto, falada na Tanzânia; o Shona, integrante do grupo de línguas niger-cordofanianas; e o Hausa, língua afro-asiática. Essas têm sido intensamente estudadas, especialmente no que diz respeito à sua fonologia. A propósito, ver Odden (1982), Myers (1987), Leben et al. (1989), Inkelas \& Leben (1990).

${ }^{4}$ Nas estratégias de conformação a OCP apresentadas em (2), levaram-se em conta apenas dois níveis de representação: a representação subjacente (R. Sub.) e a representação de superfície (R. Sup.).

${ }^{5}$ Ver Soares (1996, p.16-17).

${ }^{6}$ Encontra-se em Odden (1986, p. 363) a observação de que uma determinada classe de contra-exemplos a OCP poderia ser evitada se o princípio em questão fosse enfraquecido, proibindo somente auto-segmentos tonais idênticos e adjacentes associados a unidades portadoras de tom adjacentes. Também em Odden (1986, p.379; 381$)$ está a rejeição de OCP como princípio, por não haver provas de que esse governe amplas partes de derivações, fazendo com que sequiências de tons idênticos passem automaticamente a um único tom e tendo, com isso, um papel como uma restrição formal sobre representações fonológicas. Entre os casos em que OCP falha, os seguintes foram encontrados por Odden (1986, p. 378): a manutenção de tons idênticos situados em morfemas diferentes (como nas línguas Shona e Kishambaa); a não-imposição de restrição sobre seqüências tonais flutuantes 
em radicais (língua Kikuyu), nem sobre a combinação entre tons idênticos associados e tons flutuantes (Yala Ikom); a falta de restrição sobre tons idênticos separados por uma vogal, mas não por um tom (Yoruba); a não-existência de restrição sobre sequiências tonais associadas (Kishambaa, Temne e um dialeto do Shona); a inexistência de restrição sobre puras melodias tonais flutuantes (como a melodia recebida, no Shona, por verbos em orações subordinadas - a melodia Alto Alto- Baixo finalizada por um tom que é cópia daquele caracterizador de raízes (um tom Alto ou Baixo).

${ }^{7}$ Yip (1988, p. 65, nota 1) afirma que a maior parte dos [contra-] exemplos de Odden (1986) podem ser reinterpretados como evidência a favor de OCP, visto que muitos envolvem epêntese em seqüências idênticas ou dissimilação.

${ }^{8}$ Ver a respeito, por exemplo, Gnanadesikan (2004).

${ }^{9}$ Também há falantes de Tikuna no Peru e na Colômbia. A maior parte dos Tikuna encontra-se, porém, no Brasil, país em que constituem o maior grupo indígena.

${ }^{10}$ A restrição MAX-IO exige que o input apareça maximamente no output. Mais adiante, ver-se-á operação dessa restrição na língua Kaingáng. A MAX-IO também se faz presente na escala hierárquica proposta para a língua Parkatêjê.

${ }^{11}$ No quadro (10), as formas itimai) (M-B-A) e itimai) (A-M-A) - com tom médio associado a duas sílabas adjacentes - são possíveis candidatos a output ótimo. Sua eliminação depende do modo como é considerado o tom médio em Tikuna. Em Soares (2001), o tom médio foi interpretado não como um tom default, mas como um tom neutro , não-marcado, estando permanentemente não-especificado. Isso significa que, nessa condição, "mantém-se como transparente a processos que operam no nível tonal, não possui qualquer possibilidade de violar OCP e não é ele próprio fonte de qualquer processo" (idem, p. 32).

${ }^{12}$ Mesmo se abandonada - na concepção de $\mathrm{OCP}$ - a referência específica à noção de camada auto-segmental, tal como propõe Suzuki (1998), os dois tons altos em (11a) constituirão uma seqüência estrita, porque não mediados por outro (traço de) tom especificado. A propósito do tom médio em Tikuna, rever a nota 11.

${ }^{13}$ Ver a respeito Soares (2003).

${ }^{14}$ Cf. D'Angelis (2005).

${ }^{15}$ Wetzels (1995) formula a regra que proíbe a sequiência [coronal]/[coronal] para o Kaingáng.

${ }^{16}$ Com relação à existência fonética de consoantes nasais em contorno na língua 
Kaingáng (por exemplo, [ng], [gy]), lembramos que, devido ao fato de constituírem um único segmento com fases diferentes, sua presença na coda não configurará violação da restrição [*COMPLEX ${ }^{\text {CODA }}$ ], que proíbe coda complexa. No que diz respeito à opção de representar fonologicamente o item lexical referente à 'estrela' como contendo uma consoante nasal subjacente após vogal fonologicamente nasal, essa segue aqui D' Angelis (2005). Embora possa haver soluções alternativas a essa questão (ver, por exemplo, Wetzels (1995)), do ponto de vista de um modelo representacional como a teoria da otimalidade, seria, em princípio, irrelevante escolher /krĩy/ ou /krĩg/ como input, dado o postulado da riqueza da base assumido nessa teoria. A única (e importante) observação a ser feita nesse caso é a de que essa mesma teoria opera com a redução das distâncias entre input e output através das restrições MAX-IO e DEP-IO - que militam a favor da maior proximidade entre input e output -, o que favorece a seleção de /krĩy/ como input, tendo em vista a seleção de [krĩn] como output ótimo.

${ }^{17}$ Por limitações de espaço, eliminamos do quadro em tela as restrições (SON, MAX-IO, DEP-IO) que não estão diretamente ligadas à seleção, diante dos candidatos elencados, da forma output ótima.

${ }^{18}$ É possível afirmar que o comportamento fonológico do tepe (tap) no português do Brasil (PB) sugere sua classificação como [- anterior] - caso em que seriam dispensados os traços de abertura para dar conta do fenômeno. Isso mostra que é importante realizar uma caracterização articulatória do tepe no $\mathrm{PB}$, em termos de uma fonética fina e sua possível interpretação no âmbito de uma geometria de traços fonológicos.

${ }^{19}$ A propósito desse tema, Oliveira (2006), com base em uma releitura de Damulakis (2005), reinterpreta o que havia sido anteriormente formalizado por Damulakis (2005) em termos de dorsalidade, sugerindo que OCP atua, no português do Brasil, na redução de [ow] para [o], devido à labialidade dos segmentos, excluindo com isso uma possível redução de [aw] para [o]. Esse assunto ainda necessita de maior investigação, diante de dados como s[o]dade, [o]toridade (em lugar de saudade, autoridade), etc. Para efeitos do presente artigo, vamos tratar esse tema como uma questão ainda em aberto, referindo-nos à restrição em causa como OCP [dorsal]/ [labial].

${ }^{20}$ Cabe ressaltar que /u/ e /w/ têm as mesmas características articulatórias, diferindo entre si apenas por suas respectivas posições na sílaba.

${ }^{21}$ Ver nota 19. 


\section{Referências Bibliográficas}

ARAÚJO, L. Aspectos da Língua Gavião-Jê. 1989. 253p. Tese (Doutorado em Lingüística) - Faculdade de Letras da Universidade Federal do Rio de Janeiro, 1989.

DAMULAKIS, G. N. Fenômenos Variáveis sob uma Óptica Formal. 2005. Dissertação (Mestrado em Lingüística) - Faculdade de Letras da Universidade Federal do Rio de Janeiro, 2005.

Variação interlingüística no tronco Macro-Jê: o Kaingáng e Parkatêjê. In: RODRIGUES, A. D. (Org.). Revista Estudos da Lingua (gem). Vitória da Conquista, UESB, 2006.

D'ANGELIS, W. R. Algumas notas comparativas sobre o dialeto Kaingáng paulista. In: Encontro Internacional sobre Línguas e Culturas Macro-Jê, 4, 2005. Recife. Ms.

GNANADESIKAN, A. Markedness and faithfulness constraints in child phonology. In: KAGER, R.; PATER, J.; ZONNEVELD, W. Constraints in phonological acquisition. Cambridge, Cambridge University Press, 2004. p. 73-108.

GOLDSMITH, J. Autosegmental phonology. MIT dissertation, 1976. [ Published, New York, Garland, 1979.]

INKELAS, S.; LEBEN, W. Where phonology and phonetics intersect: the case of Hausa intonation. In: BECKMAN, M. E.; KINGSTON, J. Between the grammar and physics of speech. Cambridge, Cambridge University Press, 1990. p. 17-34.

LEBEN, W. R. Suprasegmental phonology. MIT dissertation, 1973. [Published, New York, Garland, 1980].

The representation of tone. In: FROMKIN, V. (Ed.). Tone: a linguistic survey. New York, Academic Press, 1978. p. 177-219.

LEBEN, W.; INKELAS, S. et al. Phrases and phrase tones in Hausa. In: NEWMAN, P. (Ed.). Proceedings of the Seventeenth Conference on African Linguistics. Dordrecht, Foris, 1989. p. 45-61.

MEYERS, S. Tone and the structure of words in Shona. 1987. PH.D. Dissertation - University of Massachusetts, Amherst.

MEYERS, S. OCP effects in Optimality Theory [1995]. In: MCCARTHY, J. J. Optimality Theory in phonology: a reader. Oxford, Blackwell, 2004. p. 246-267.

ODDEN, D. Tonal phenomena in Kishambaa. Studies in African Linguistics, 13, p. 177-208, 1982.

On the role of the Obligatory Contour Principle in phonological theory. Language, v. 62, n. 2, p. 353- 383, 1986. 
OLIVEIRA, A. M. Inserção e apagamento de [w] em coda: uma análise pela Geometria de Traços. 2006. Dissertação (Mestrado em Língua Portuguesa) Faculdade de Letras da Universidade Federal do Rio de Janeiro, 2006.

SOARES, M. F. O supra-segmental em Tikuna e a teoria fonológica. v.2. 1992. Ritmo. Tese (Doutorado) - IEL, UNICAMP, Campinas, 1992.

Regulação rítmica e atuação do OCP em Tikuna. Letras de Hoje. Porto Alegre, v. 31, n. 2, p. 7-26, 1996.

. A contribuição do Tikuna às regras do ritmo e à relação sintaxe-fonologia. In: SCARPA, E. M. (Org.). Estudos de prosódia no Brasil. Campinas, Editora da UNICAMP, 1999. p. 189-252.

. Subespecificação tonal e tom default: o caso Tikuna. In: CABRAL, A.S.; RODRIGUES, A.D. (Org). Estudos sobre Línguas Indígenas I. Belém, Universidade Federal do Pará, 2001.

. Línguas indígenas: caminhos de uma investigação. Letras de Hoje. Porto Alegre, v. 38, n. 4, p. 63-88, 2003.

SUZUKI, K. A typological investigation of dissimilation. 1998. PhD dissertation, University of Arizona, 1998.

WETZELS, Leo (Org.). Estudos fonológicos das línguas indígenas brasileiras. Rio de Janeiro: Editora UFRJ, 1995.

YIP, M. The Obligatory Countour Principle and phonological rules: a loss of identity. Linguistic Inquiry, v. 19, n. 1, p. 65-100, 1988. 